\title{
Accumulation of glomalin-related soil protein benefits to soil carbon sequestration with tropical coastal forest restoration
}

\author{
Jing Zhang ${ }^{1}$, Jian $\mathrm{Li}^{1}$, Lingling $\mathrm{Ma}^{1}$, Xinhua $\mathrm{He}^{2}$, Zhanfeng Liu ${ }^{1}$, Faming Wang ${ }^{1}$, XL \\ Tang $^{1}$, and Guowei $\mathrm{Chu}^{1}$ \\ ${ }^{1}$ South China Botanical Garden \\ ${ }^{2}$ University of California Davis
}

February 15, 2021

\begin{abstract}
Reforestation is widely used to restore degraded infertile soils in the coastal area. Substantial attention has been paid to the functioning of $\mathrm{AMF}$ in vegetation restoration because arbuscular mycorrhizal fungi (AMF) are considered beneficial to this process. However, little is known about the effect of AMF product, glomalin-related soil protein (GRSP), on soil organic carbon (SOC) sequestration during the forest restoration. We conducted a study in a tropical region where the native forest has been seriously deforested with only a few grasses and then a series of restoration approaches have been made to restore the forest ecosystem. The study sites include a barren land (BL), a Eucalyptus exserta planted forest (EF), a mixed broadleaved forest (MF) and a secondary natural forest (SF), which represents the un-, early-, middle- and late-restoration stage, respectively. The results showed that the restoration increased EE-GRSP and T-GRSP by 3.9-12.3 times and 1.9-4.6 times compared with the barren land, respectively. The proportion of GRSP in SOC is 1.6-2.0\% (EE-GRSP/SOC) and 6.5-15.8\% (T-GRSP/SOC), respectively. Also, a significantly positive relationship was found between the proportion of GRSP in SOC and recalcitrant SOC composition percentage (aromatic C), as well as between GRSP and soil aggregate stability. These results together suggest that the restoration of the degraded tropical forest is beneficial to soil C sequestration with the accumulation of GRSP, most likely, through an improvement of the soil aggregate stability and increase of the proportion of recalcitrant soil $\mathrm{C}$ chemical composition.
\end{abstract}

\section{Hosted file}

main text-LDD.pdf available at https://authorea.com/users/395891/articles/508989accumulation-of-glomalin-related-soil-protein-benefits-to-soil-carbon-sequestrationwith-tropical-coastal-forest-restoration 


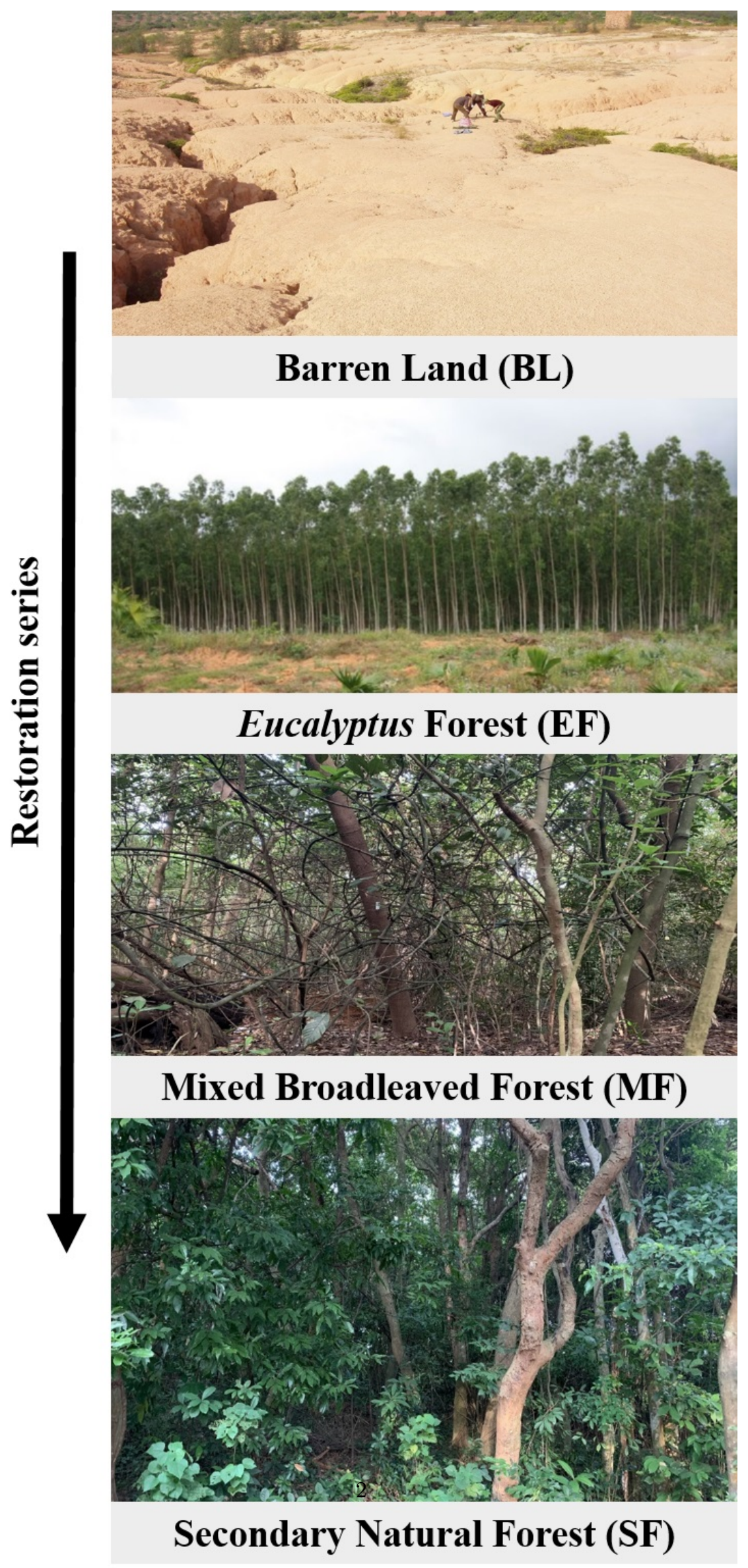



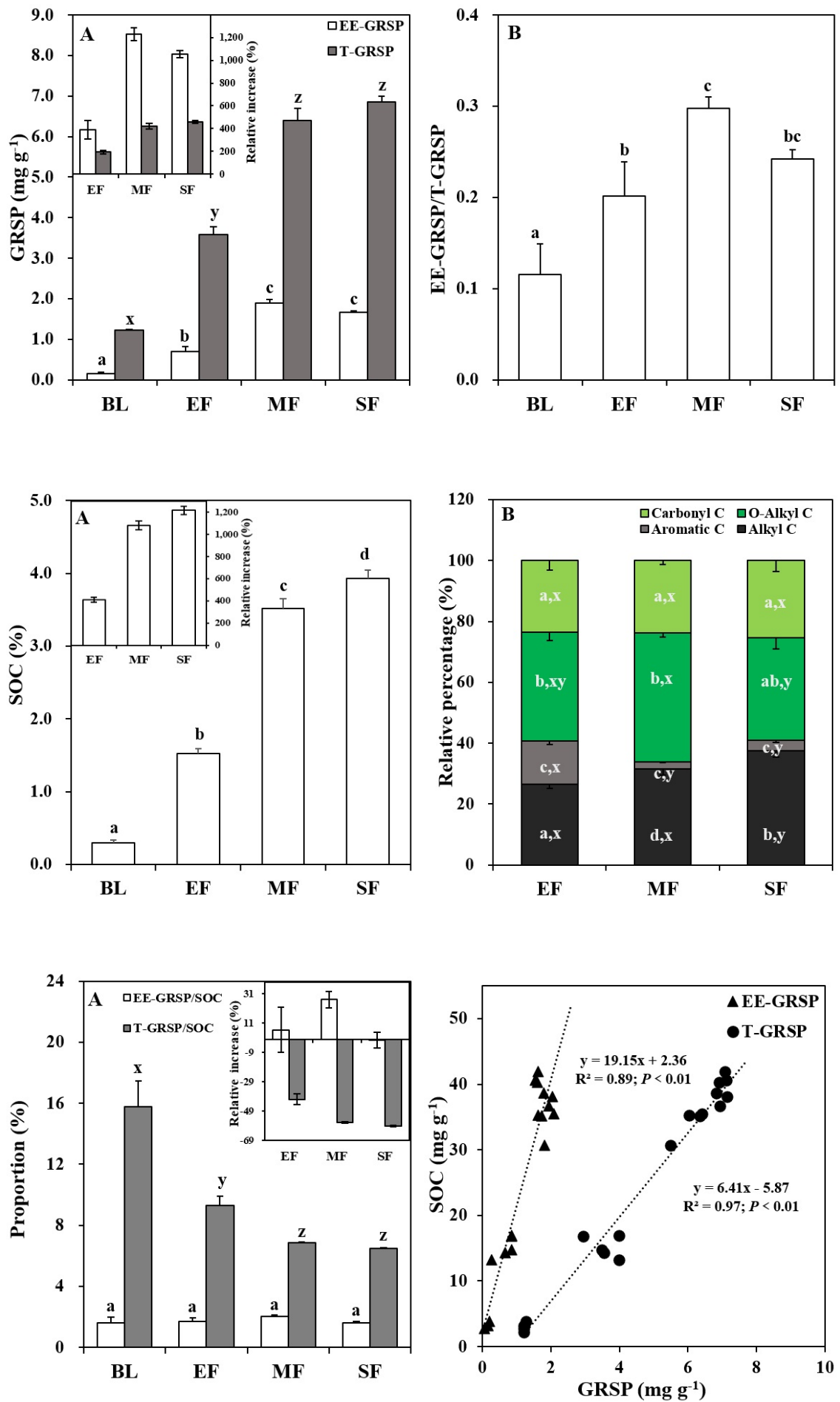

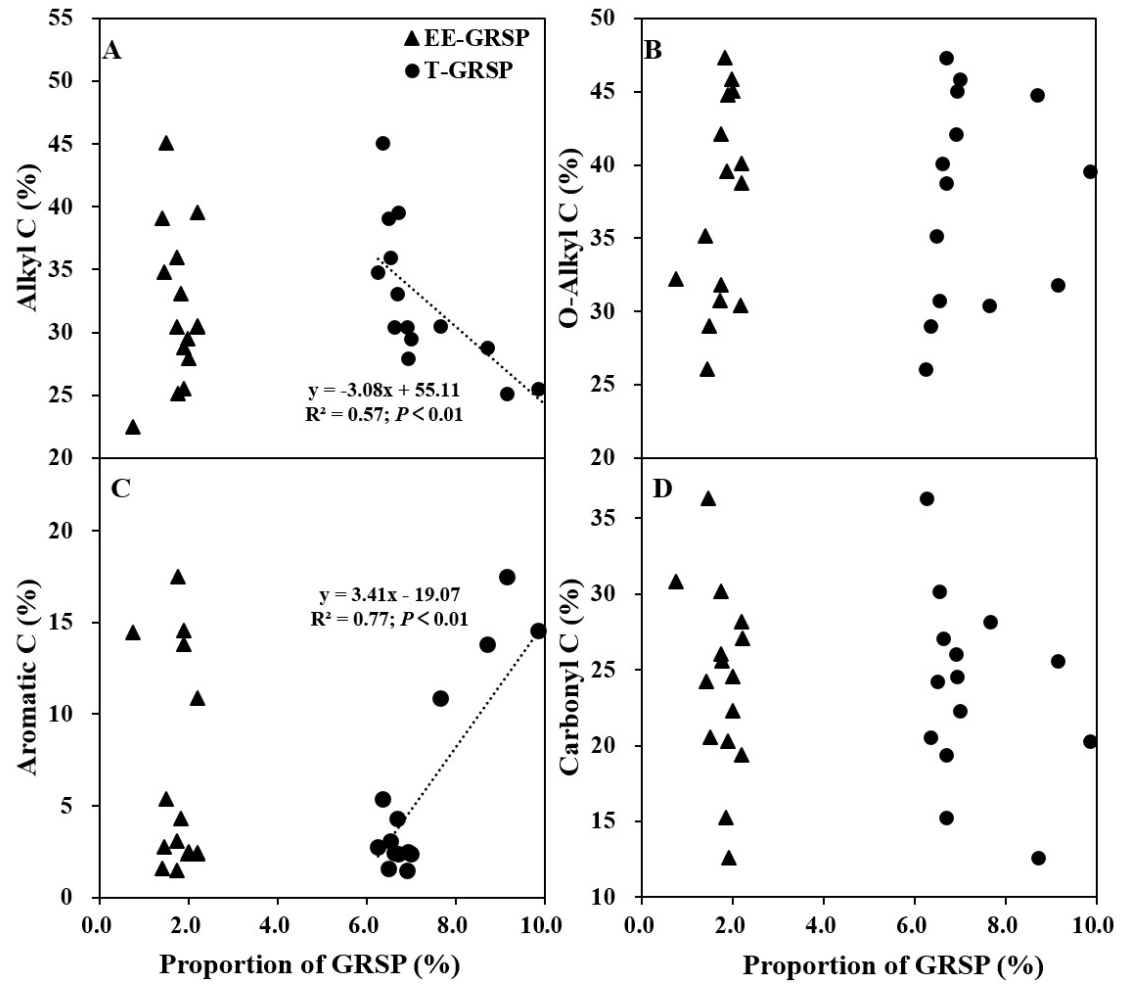